\title{
Control \& Prediction: Reexamining the 2008-2009 US Banking Crisis
}

\author{
By Kenneth J. Hatten * \\ James P. Keeler \\ William L. James
}

US banks experiencing losses during the 2008-2009 financial crises quickly returned to profitability. What does managerial control contribute to re-establishing performance? Return on equity (ROE) for 1200 banks that survived the crisis is evaluated by degree of control and leverage from 2001 through 2011. We estimate a performance equation and find that both control, measured as the coefficient of variation of ROE, and leverage have significant effects on ROE: control negative, leverage positive. Control affects the patterns of ROE across time; leverage does not. The ability of the estimate to account for and predict ROE holds up well through the crisis but only for banks with tight managerial control. As control loosens, the performance of the estimate deteriorates. During the financial crisis, tightening control improved profitability. The persistent influence of managerial control on ROE is discriminating. Prior performance predicts future performance but only for tightly controlled banks.

Keywords: Bank Profitability, Control, Financial Crisis, JEL Codes: D22- G17- G21, Leverage, Partitioned Data.

\section{Introduction}

The turbulence of the 2008/2009 financial crisis was outside of normal banking experience as the traces of the annualized mean quarterly bank return on equity (ROE) and its standard deviation in Figure 1 imply. The volatility of ROE between 2007 and 2011 was so much larger than the changes experienced from 1990 until 2007 that it is worth noting that, despite the turbulence, $70 \%$ of the USA's largest banks circa 2011 were able to avoid an annual loss in both 2008 and 2009.

\footnotetext{
*Professor Emeritus, Boston University, USA.

†Professor Emeritus of Economics, Kenyon College, USA.

${ }^{*}$ Robert E. Brockway Distinguished Professor of Marketing \& International Business, Hofstra University, USA.
} 
Figure 1. The Historic Profitability of the Top 1200 US Banks of 2011, 1991-2011

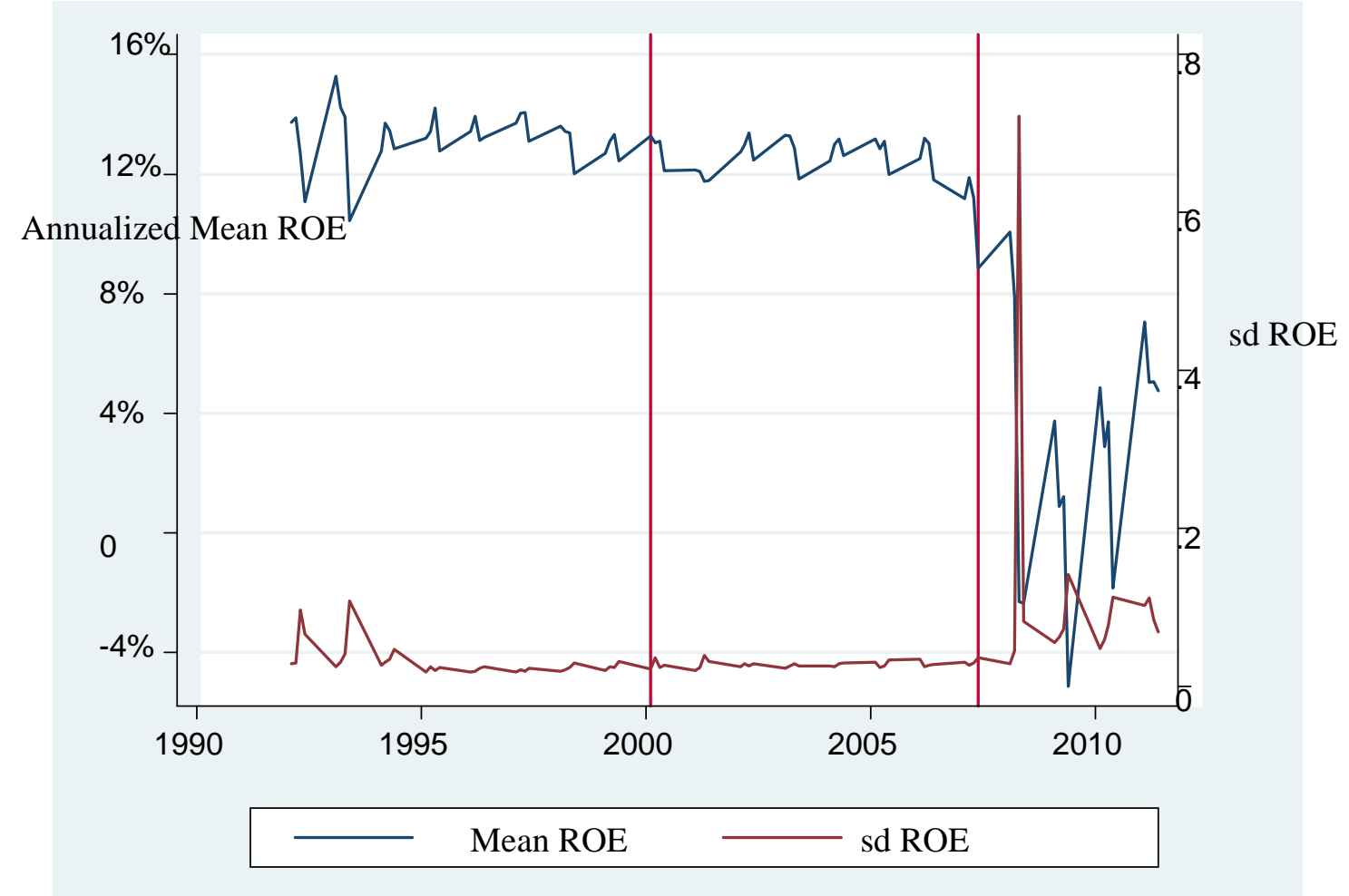

Source: Author.

As Figure 2 shows, 442 banks among the approximately 1200 largest survivors of 2011 still reported one or more quarterly losses in 2008 and 2009. On average, however, America's banks dealt with the negative effects of the crisis quickly. Most of these banks (284) "recovered" and returned to profitability, reporting only one quarterly loss in the two crisis years. It is also impressive that $368,83 \%$ of the 442 , recovered without a loss in any third quarter. Note, again, the greater majority of US banks did not report an annual loss in 2008 and 2009.

\section{Figure 2.}

\begin{tabular}{|l|c|c|c|c|c|c|c|c|c|}
\hline \# Banks with 2008 Q & 250 & 284 & & & & & & & \\
\hline & 200 & & & & & & & & \\
\hline & 150 & & & & & & & & \\
\hline & 100 & & & & & & & & \\
\hline & 50 & & 84 & & & & & & \\
\hline & 0 & & & 40 & 19 & 8 & 3 & 2 & 2 \\
\hline & & 1 & 2 & 3 & 4 & 5 & 6 & 7 & 8 \\
\hline & & \multicolumn{7}{|c|}{ \# loss Quarters, 2008 and 2009 } \\
\hline
\end{tabular}

Source: Author.

Figure 2 reports that only 15 of the approximately 1200 surviving banks in our sample suffered losses in more than four quarters. In general, banks experiencing quarterly losses during the crisis were able to limit them and re- 
establish control and profitability. This observation leads to our research questions: What role did managerial control play in determining ROE in the 2008-2009 financial crises? Did control have a larger role than leverage (Assets/Equity) in determining ROE?

\section{Control}

Let us clarify what we mean by 'control.' Fayol (1916), for example, and much later, Anthony (1965), wrote about planning and control, not corporate governance which is to say ownership. And, of course, there is a substantial body of literature on the control of manufacturing operations, total quality management and the fulfillment process, knowledge of its normal variance, and systematic variance reduction where it is called for by the market in the quest for higher quality output (Shewhart 1984, Walton 1986, Juran 1989).

Anthony (1965) pointed out that in a well-managed company; control is about understanding and managing variance. It is not about conformance with plan or minimizing variance:

"We emphasize that such a concept is antithetical to our view if middle management can do better than plan, top management wishes it to do so. Top management is neither clairvoyant nor omniscient so results will differ from plan. Top management wants middle management to react to events that actually occur. Plans are only what looked like the best course of action. Some may see ways to improve on plan as facts and alternatives become clearer. Conformance to plans is not the standard by which performance should be measured to do otherwise would stifle initiative and encourage unthinking mediocrity." (Anthony 1965: 29-31)

For Anthony, and the authors, variance carries information about what to avoid and opportunities to seize. The facts that the standard deviation is two sided and the control objective is not variance minimization support our proposition that some other measure of profit volatility may be a useful control proxy in research on bank profitability.

How is variation measured? In their multi-industry study, Dichev and Tang (2009) chose to analyze their data with an autoregressive model tying current to prior earnings. They used the variance of ROA as a measure of volatility to explore the predictability of earnings. One of their findings was that earnings volatility was inversely related to earnings. We considered using either the standard deviation or the variance of ROE but recognized their limits, in particular, within a large data base study, the difficulty of interpreting either. For this reason, we adopted the absolute value of the coefficient of variation of $\operatorname{ROE}(\sigma / \mu)$, hereafter known as ACV, as our measure.

A small ACV corresponds to tight control, a large ACV with lose control. $\mathrm{ACV}$ is therefore easy to interpret, being the percentage variation of ROE relative to its mean. It is a sensitive measure closely tied to earnings and, as Gopalan (2010) found, a deterioration of earnings was the earliest predictor of bank failure 
among several possible candidates he studied - the deterioration occurring 14 quarters ahead of failure. Because we used the absolute value of the coefficient of variation, variation from the mean is noted, not whether it is positive $(+)$ or negative $(-)$. An advantage of the absolute measure is that negative coefficient of variation cannot be interpreted incorrectly by computers as indicating tightly controlled operation.

Using ACV also avoids confusion associated with the mistaken use of variance as a risk measure in prior research. The variance of profitability was used as a risk proxy in the strategic management literature for a time, an effort triggered by Bowman (1980). Its insights are well represented by Bromiley et al. (2001) and Nickel and Rodriguez (2002). However, we note that Bowman's methodology was appropriately criticized by Marsh and Swanson (1984) and later by Ruefli (1990). Note several years earlier that Rothschild and Stiglitz (1970, 1971) commented specifically on errors related to misinterpretations of the variance of ROE as a risk measure.

\section{Research Plan}

Observers have attributed the 2008/2009 crisis to a banking system that was hyper-leveraged (Calomiris and Meltzer, 2014). Bankers, pundits roar, were reckless. But the facts are that most banks were not hyper-leveraged (see Appendix 1, Table A1.1 for data describing the first nine leverage deciles) and their real estate investments were limited (Bartlett and King 2008). The problem discussed by Calomiris and Meltzer (2014) was less about the average US bank and more about shadow banking across the economy and real estate speculation in a few states (Gopalan 2010, Robinson 2010, Papanikolaou and Wolff 2014). With respect to the banks that reported losses during the crisis, perhaps too many of them went about their business assuming that yesterday's performance would predict tomorrow's.

Table A1.1. ACV RECORD 2001-2011(The Data Were Separately Sorted by ACV from Tight (Small) to Lose (Large) in Each Year and Then Partitioned Into Ten Cohorts of Equal Size.)

\begin{tabular}{|l|c|c|c|c|c|c|c|c|c|}
\hline Year & \multicolumn{3}{|c|}{ Cohorts 1, 2, 3 } & \multicolumn{3}{c|}{ Cohorts 4, 5, 6 } & \multicolumn{3}{c|}{ Cohorts 7, 8, 9 } \\
\hline & mean & min & max & mean & min & max & mean & min & max \\
\hline 2001 & .0582 & .0047 & .0891 & .1286 & .0892 & .1750 & .2838 & .1750 & .5161 \\
\hline 2002 & .0552 & .0019 & .0870 & .1281 & .0871 & .1766 & .2971 & .1767 & .5403 \\
\hline 2003 & .0543 & .0043 & .0869 & .1253 & .0869 & .1753 & .2884 & .1753 & .5008 \\
\hline 2004 & .0548 & .0029 & .0862 & .1212 & .0862 & .1628 & .2554 & .1630 & .4311 \\
\hline 2005 & .0487 & .0047 & .0755 & .1069 & .0755 & .1443 & .2282 & .1444 & .4141 \\
\hline 2006 & .0475 & .0046 & .0736 & .1027 & .0736 & .1367 & .2246 & .1368 & .4102 \\
\hline 2007 & .0562 & .0019 & .0872 & .1226 & .0873 & .1700 & .2763 & .1701 & .5007 \\
\hline 2008 & .0783 & .0065 & .1269 & .1926 & .1269 & .2830 & .5106 & .2833 & 1.004 \\
\hline 2009 & .1246 & .0132 & .2043 & .3356 & .2043 & .5199 & .9227 & .5201 & 1.5756 \\
\hline 2010 & .0970 & .0025 & .1620 & .2762 & .1621 & .4385 & .8564 & .4405 & 1.4782 \\
\hline 2011 & .0850 & .0047 & .1389 & .2086 & .1391 & .3061 & .6228 & .3062 & 1.2632 \\
\hline
\end{tabular}

Source: Author. 
Research by the Federal Reserve Banks and the Government Accountability Office (2013) on bank failures makes it clear that the most failures were fastgrowing banks that violated the 2006 interagency guidelines for commercial real estate loans (GAO 2013). The number of failures was small as a percentage of US banks but the failure rate for these banks was 46 times the rate of failure of banks observing the guidelines (Calabia 2016). Many of these same banks were reliant on expensive sources of funds such as wholesale deposits since their core deposits could not fund their high growth rates (Fahlenbrach et al. 2012, GAO 2013).

We wondered under what circumstances does the normally safe assumption hold in the banking industry that, on average, today's results predict tomorrow's? Second, we asked, how does control influence those results? Note that Fahlenbrach et al. (2012) in their study of several hundred banks show that bank performance after the Russian default (and the subsequent rescue of Long Range Capital Management) was consistent with performance ten years after in the 2008-2009 crisis. They attributed the persistence of both strong and poor performance over those ten years to the persistence of bank culture and risk taking proclivities. In their study, they noted that failures were more likely to be highly leveraged banks.

With these thoughts in mind, we repeat our research questions: What role did managerial control play in determining ROE in the 2008-2009 financial crises? Did control have a larger role than leverage (Assets/Equity) in determining ROE? Our plan is to examine bank ROE from 2001 to 2011, that is through the 20082009 crisis and the first years of the recovery. Rather than studying failures, we determined to study survivors. The tests of our model are, first, its fit with the data across time for banks managed with tight versus lose control and, second, its ability to predict the industry's results of 2008 through 2011, again, for banks operating with different levels of control.

\section{Data}

Our data set, one of the largest available, is the twenty-year record of approximately 7000 US banks maintained by Highline Financial (formerly owned by Thompson Reuters). We restricted our investigation to the 1200 largest surviving banks of 2011 - that is banks with assets greater than $\$ 520$ million in 2011 and so economically more relevant than smaller banks. The panel data we used describes the financial footprints of these banks from 2001 through 2011. The largest bank in the study had assets of $\$ 1.3$ trillion in 2011. Clearly our data extend through the 2008/2009 crisis.

ROE and ACV are defined as the ROE of one quarter with the mean ROE and its standard deviation calculated over that and the prior three quarters, four in all. ACV is defined by the absolute value of the standard deviation of ROE divided by its mean and, since these are sample measures, the precise definition is the absolute value of ( $\mathrm{S}_{\mathrm{ROE}} / \overline{\mathrm{RO}}$.

As a first step, we deleted 5 observations which had $\mathrm{ACV}<=0$. Then we trimmed as follows: on the variable ROE, we deleted the lowest $2 \%$ and the highest $1 \%$; on ACV we deleted the highest 5\%; and on leverage (henceforth LEV) we deleted the lowest $1 \%$ and the highest $5 \%$. These decisions were guided 
by histograms to make the distributions of these variables more normal in appearance and to reduce extreme Kurtosis values. (ACV being an absolute quantity can't be normally distributed.) Such steps are common practice in large data base studies and they allowed us to focus our research on core US banking institutions. In this trim, we point out that we eliminated cases - specific observations of banks in specific quarters, not entire banks.

Our second step was to partition the data by deciles. Each decile had about 4200 cases. We sorted the data first by control, with ACV from small values (tight control) to large values (lose control) and, then, separately by leverage, with LEV from light to heavy. Partitioning is more flexible than using dummy variables and interactions, and we have plenty of degrees of freedom so the sacrifice of efficiency is small. Partitioning avoids constraining the analyses by assuming universal constants and a shared slope for either of the two independent variables. Furthermore, this strategy avoids taking an intermediate position by assuming $a$ priori different intercepts but common slopes. Finally, it ensures that we can address the research questions, and determine whether, and for which classes of bank, ACV or LEV had the greater effect on ROE.

We then analyzed each partitioned set data separately. In the ACV partitioned data, ACV is restricted to a narrow range within each decile or cohort while LEV has its full ten-decile range (6.12 to 18.45$)$. In the leverage partitions, LEV is restricted within each ordered decile and ACV has its full ten decile range (0.0019 to 1.5756$)$.

\section{Preliminary Analysis}

Table 1 provides snapshots of the ROE of the partitioned data in 2007 and in 2009, at the beginning and end of the crisis as defined by the National Bureau of Economic Research. Clearly, as Table 1 shows, returns vary with ACV and, in the separately ordered LEV cohorts, with LEV. To save space, we have combined our original decile partitions into sets of three. For the ACV cohorts, the tightly controlled set includes 1,2 and 3, the next set is 4,5 and 6, and the last and least controlled set is 7,8 and 9. We believe that this consolidation to three large equally-sized large cohorts faithfully presents our analysis. In omitting cohort 10, we omitted $10 \%$ of the banks in our study, specifically those with, respectively, far wider ranges of ACV or LEV than observed in the first nine cohorts.

Table 1. Direct Profit Impact of Crisis

\begin{tabular}{|l|c|c|c|c|c|c|c|c|}
\hline $\begin{array}{l}\text { Cohort } \\
\text { Deciles }\end{array}$ & \multicolumn{2}{|c|}{$\begin{array}{c}\text { Actual } \\
\text { Quarterly } \\
\text { ROE }\end{array}$} & & & \multicolumn{3}{c|}{$\begin{array}{c}\text { Actual } \\
\text { Quarterly } \\
\text { ROE }\end{array}$} & \\
\hline & & \multicolumn{2}{|c|}{$\boldsymbol{C V}$} & Drop & & \multicolumn{2}{|c|}{ LEV } & Drop \\
\hline & & $\mathbf{2 0 0 7}$ & $\mathbf{2 0 0 9}$ & & & $\mathbf{2 0 0 7}$ & $\mathbf{2 0 0 9}$ & \\
\hline & Control & & & & Leverage & & & \\
\hline $1,2,3$ & Tight & .0353 & .0290 & $\mathbf{1 7 . 8 \%}$ & Light & .0230 & .0132 & $\mathbf{4 2 . 6 \%}$ \\
\hline $4,5,6$ & Moderate & .0321 & .0189 & $\mathbf{4 1 . 1 \%}$ & Moderate & .0294 & .0173 & $\mathbf{4 1 . 2 \%}$ \\
\hline $7,8,9$ & Loose & .0241 & .0088 & $\mathbf{6 3 . 5 \%}$ & Heavy & .0319 & .0209 & $\mathbf{3 4 . 5 \%}$ \\
\hline
\end{tabular}

Source: Author. 
Table 1 shows the decline in bank ROE between 2007 and 2009 during the financial crisis. On the left hand side of Table 1 the data are partitioned by ACV (Control) from tight control at the top to lose control at the bottom. On the right, the data are partitioned by LEV, from lightly leveraged banks at the top to the more heavily leveraged banks at the bottom. From Table 1, it is clear from the average ROE earned by banks in each of the 3 decile ACV cohorts that tightly controlled banks (1, 2 and 3) had higher returns (ROE) than more loosely managed banks both in 2007 and in 2009 (the low profit year in the banking crisis). The crisis impact on ROE was a drop of $17.8 \%$ for the tightly managed cohorts and a much larger drop of $63.5 \%$ for the looser. Going forward, then, we expect ACV to be inversely (negatively) related to ROE. More detailed ROE data are available in Appendix 1, Table A1.2.

Table A1.2.Cohorts Structured Year by Year Quarterly Mean ROE RECORD of ACV PARTITIONED COHORTS. Low Rank Deciles Have Low Acvs and so Represent Tight Control

\begin{tabular}{|c|c|c|c|c|c|c|c|c|c|c|c|}
\hline \multirow{2}{*}{$\begin{array}{l}\text { Cohort } \\
\text { Deciles }\end{array}$} & 2001 & 2002 & 2003 & 2004 & 2005 & 2006 & 2007 & 2008 & 2009 & 2010 & 2011 \\
\hline & & & & & & & & & & & \\
\hline $1,2,3$ & .0373 & .0393 & .0382 & .0387 & .0377 & .0375 & .0353 & .0336 & .0290 & .02885 & .0284 \\
\hline $4,5,6$ & .0342 & .0359 & .0351 & 0345 & .0341 & .0342 & 0321 & .0262 & .0189 & .0232 & .0240 \\
\hline $7,8,9$ & .0289 & .0307 & .0283 & .0292 & .0311 & .0288 & 0241 & .0162 & .0088 & .0115 & .0150 \\
\hline & & & & & & & & & & & \\
\hline
\end{tabular}

For the LEV cohorts, Table 1 reveals that the more leveraged cohorts, specifically the 'LEV' cohort 7, 8, 9, enjoyed the highest ROE. Moreover, it is also clear that the crisis impacted these banks less than their less leveraged rivals an ROE drop of $34.5 \%$ for the most leveraged banks versus the $42.6 \%$ drop of the least leveraged banks. This simple analysis reveals that in this sample population, the more leveraged banks consistently out-performed the lightly leveraged, both before and through the crisis, suggesting that classically defined bank leverage (Assets/Equity) per se was not the systemic problem shaping the crisis (Calomiris and Meltzer, 2014). Fahlenbrach et al. (2012, p. 2166) reported that leverage had a positive relationship with bank performance. For all of these reasons we expect LEV to be positively related to ROE.

\section{Significance and Predictability}

In this study with its focus on control and leverage, our purpose was to determine whether the two independent variables, ACV (control) and LEV, have statistically significant coefficients in a regression estimate of ROE and, where they do, to note the relative size of their impacts on ROE. Thus, we used a deliberately simple model focused on these two variables of interest, ACV and leverage: 


\section{$\mathrm{ROE}=\mathrm{F}(\mathrm{ACV}, \mathrm{LEV}, 12$ statistical controls and 6 to 10 time effects) (1)}

The statistical controls in Equation (1) are 12 variables describing the banks and their market strategies. These are included to ensure that the effect of the two theoretically interesting variables, ACV and LEV, are not biased. The six- to tentime effects represent the macro environment. In the first set of estimates, 20012007, we included six time effects, one for each year in the estimate but one. To facilitate interpretation, we deliberately choose 2007 as the referent year for each set of estimates since it was the year that marked the peak of the business cycle preceding the 2008-2009 crises. The number of time effects included increased from 6 to 10 as we moved out to 2011.

We expected a negative coefficient for ACV on the notion that tighter control improves ROE and we expect a positive coefficient for LEV as greater leverage, ceteris paribus, should increase ROE. These expectations are, of course, consistent with the preliminary analysis reported in Table 1 above. The twelve statistical controls that allow us to include bank and market factors are listed and defined in Table 2 and are also drawn from Highline Financial. They describe bank income and expenses, their asset and liability structures and their income sources. As implied above, some of these statistical control variables, e.g., rev2ta, oi2rev, and depratio (see Table 2), describe both the markets served by particular banks, as well as the banks themselves.

Beyond establishing the significance of ACV and LEV, we were interested in the fit $\left(\mathrm{R}^{2}\right)$ achieved by our model. In addition, we planned to assess how well Equation 1 predicted the profitability of banks through the 2008-2009 crisis and beyond to 2011, cohort by cohort. Thus, we will report both $\mathrm{R}^{2}$ and predictions for the model estimated on the 2001-2007 data and then for models estimated on 2001 to 2008 , and every additional year to 2010 as that year's data are added to the estimation basis. This approach will make it clear whether and to what extent the hypothesized relationships between ROE and our independent variables are persistent across time.

Table 2. The Statistical Controls

\begin{tabular}{|l|c|}
\hline Inta & Ln of Total Assets \\
\hline spread & $\begin{array}{c}\text { Interest Earned/(Loans + Securities) - Interest Paid/Interest Bearing } \\
\text { Deposits }\end{array}$ \\
\hline lossexp & Provision for Loan Losses/Total Loans \\
\hline taxrate2 & Taxes/Earnings Before Tax \\
\hline investratio & Loans/Total Assets \\
\hline rev2ta & (Interest Income + Other Income)/Total Assets \\
\hline oi2rev & Other Income/(Interest Income + Other Income), i.e., Other \\
& Income/Revenue \\
\hline depratio & Demand Deposits/Total Deposits \\
\hline int2dep & Interest Paid/Interest Bearing Deposits \\
\hline refract & Real Estate Income/Interest Income \\
\hline sal2emp & Salary per Employee \\
\hline salfract & Salary/Other Expenses, i.e., Non-Interest Expenses \\
\hline
\end{tabular}


By presenting the 2001-2007 results for both the ACV and LEV partitions, we hope to establish the value of the model and gain further insight into the relative impacts of ACV and LEV on ROE. By repeating the model estimation and predictions by adding each extra year to the estimation base, we will assess its stability across time and replicate the efforts of a banker, regulator or analyst, projecting one year into the future. If the same model fits year after year for the different cohorts as measured by $\mathrm{R}^{2}$ and if that fit is confirmed by the model's performance as a predictor of subsequent profitability, we can conclude whether and for whom the system is relatively stable. Consistent fit and the gaps between prediction and actual ROE will have meaning because they will allow us to assess the stability of the model and the predictability of banking when control is tight or loose.

\section{Estimation and Results}

Preliminary analysis showed that fixed effects apply and that the residuals were serially correlated. Serial correlation does not bias coefficient estimates, but it does bias the estimates of their standard errors causing distortions in t-values, and so, in turn, potentially leading to inappropriate decisions about significance. To deal with this problem, we included two lags of the dependent variable, ROE, in our model, that being a standard way to address serial correlation.

The results show that the two lags of ROE have large $\beta$ values and are highly significant. The estimated $\beta$ coefficients of these lags are, however, substantially less than one so the model is dynamically stable. On the surface of things, the lags of ROE contribute to the fit and predictive performance of the model. But our results also showed that our primary variables, ACV and LEV, as well as many of our statistical controls and time fixed effects had significant coefficients in fairly consistent patterns. These results collectively indicate that our model has managed the serial correlation characterizing banking, giving us confidence that the estimates claimed as significant are in fact significant.

The upper half of Table 3 reports the estimated $\beta$ coefficients for ACV when the data was partitioned by ACV. ACV was almost always significant and negative in these regressions whether estimated on the 2001-2007 bases or on longer time lines as Table 3 shows. There was one exception, that being in the ACV series (Table 3) for the 4, 5, 6 cohort in the 2001-2009 $\beta$ estimate for ACV. Note that otherwise, the estimated $\beta$ coefficients for ACV were largest in the 2001-2009 regressions. LEV always had a positive sign in the ACV partitioned estimates. 
Table 3. ACV Partitioned Data -- Estimated $\beta_{A C V}(p$ value)

\begin{tabular}{|l|c|c|c|c|c|c|}
\hline ACV range & $\begin{array}{c}\text { Cohorts } \\
\text { Deciles }\end{array}$ & $\begin{array}{c}\mathbf{2 0 0 1 - -} \\
\mathbf{2 0 0 7}\end{array}$ & $\begin{array}{c}\mathbf{2 0 0 1 -} \\
\mathbf{2 0 0 8}\end{array}$ & $\begin{array}{c}\mathbf{2 0 0 1 -} \\
\mathbf{2 0 0 9}\end{array}$ & $\begin{array}{c}\mathbf{2 0 0 1 -} \\
\mathbf{2 0 1 0}\end{array}$ & $\begin{array}{c}\mathbf{2 0 0 1 -} \\
\mathbf{2 0 1 1}\end{array}$ \\
\hline $.0474-$ & \multirow{2}{*}{$1,2,3$} & -.0049 & -.0064 & -.0084 & -.0061 & -.0055 \\
.1246 & .004 & .000 & .000 & .000 & .000 \\
\hline $.1027-$ & \multirow{2}{*}{$4,5,6$} & -.0066 & -.0065 & -.0021 & -.0059 & -.0054 \\
.3356 & .018 & .007 & .339 & .002 & .001 \\
\hline $.2246-$ & \multirow{2}{*}{$7,8,9$} & -.0070 & -.0147 & -.0100 & -.0079 & -.0069 \\
.8564 & & .000 & .000 & .000 & .000 & .000 \\
\hline
\end{tabular}

Source: Author.

Table 4 reports the $\beta$ estimates for LEV when the data were partitioned by LEV. Here, LEV was always significant and positively signed. The size of these $\beta$ coefficients tended to decline slightly as the basis for estimation extended beyond 2007 towards 2011. We can also report that ACV was also universally significant in the LEV series of regressions. In a total of 60 estimates, therefore, ACV was significant and negative in 58 while LEV was universally significant and positive. In our regressions (30/30) instances in 2 series (ACV and LEV) X 3 cohorts X 5 (years), ACV and LEV had the expected signs in all but one estimate.

Table 4. Leverage Partitioned Data -- Estimated $\beta_{L E V}$ ( $p$ value)

\begin{tabular}{|l|c|c|c|c|c|c|}
\hline LEV range & $\begin{array}{c}\text { Cohorts } \\
\text { Deciles }\end{array}$ & $\begin{array}{c}\mathbf{2 0 0 1 - -} \\
\mathbf{2 0 0 7}\end{array}$ & $\begin{array}{c}\mathbf{2 0 0 1 -} \\
\mathbf{2 0 0 8}\end{array}$ & $\begin{array}{c}\mathbf{2 0 0 1 -} \\
\mathbf{2 0 0 9}\end{array}$ & $\begin{array}{c}\mathbf{2 0 0 1 -} \\
\mathbf{2 0 1 0}\end{array}$ & $\begin{array}{c}\mathbf{2 0 0 1 -} \\
\mathbf{2 0 1 1}\end{array}$ \\
\hline \multirow{2}{*}{$6.11-10.19$} & \multirow{2}{*}{$\mathbf{1 , 2 , 3}$} & .0021 & .0021 & .0020 & .0018 & .0018 \\
& .000 & .000 & .000 & .000 & .000 \\
\hline \multirow{2}{*}{$8.83-11.96$} & \multirow{2}{*}{$\mathbf{4 , 5 , 6}$} & .0018 & .0018 & .0017 & .0016 & .0015 \\
& \multirow{2}{*}{$\begin{array}{l}.000 \\
10.34-\end{array}$} & .0018 & .000 & .000 & .000 & .000 \\
14.01 & $\mathbf{7 , 8 , 9}$ & .000 & .000 & .0016 & .0015 & .0014 \\
\end{tabular}

Source: Author.

Having established that ACV and LEV were both significant no matter the partitioning strategy, we turn to Tables 5 and 6 to report on the fit of our models, first for the ACV partitioned estimates. Table 5 reports the $\mathrm{R}^{2}$ of Equation 1 and Table 6 the $\beta$ estimates for the two lags of ROE for 2007 and then for 2011 for these ACV cohorts. Again, the measure of fit is the $\mathrm{R}^{2}$ of the model.

Table 5. Record of $R^{2}$ for Each Set of ACV Cohort Regressions 'General' Form of Model is ROE = F (Roe L1.Roe, L2.Roe, ACV, LEV, 18 to 22 Controls)

\begin{tabular}{|l|c|c|c|c|c|}
\hline \multirow{2}{*}{$\begin{array}{l}\text { Cohort } \\
\text { Deciles }\end{array}$} & \multicolumn{5}{|c|}{$\mathbf{R}^{\mathbf{2}}$ Estimated on data 2001 to designated year } \\
\cline { 2 - 6 } & $\mathbf{2 0 0 7}$ & $\mathbf{2 0 0 8}$ & $\mathbf{2 0 0 9}$ & $\mathbf{2 0 1 0}$ & $\mathbf{2 0 1 1}$ \\
\hline $1,2,3$ & .925 & .925 & .923 & .930 & .931 \\
\hline $4,5,6$ & .728 & .736 & .750 & .748 & .755 \\
\hline $7,8,9$ & .417 & .412 & .413 & .423 & .000 \\
\hline
\end{tabular}

Source: Author. 
Table 6. ACV Cohort Regressions $\beta$ Estimates for the First Two Lags of ROE 'General' Form of Model is ROE=f (Roe L1.Roe, L2.Roe, ACV, LEV, With 18 to 22 Controls)

\begin{tabular}{|l|c|c|c|c|}
\hline & \multicolumn{2}{|c|}{$\boldsymbol{\beta} 2001-2007$} & \multicolumn{2}{c|}{$\boldsymbol{\beta} 2001-2011$} \\
\hline Cohort Deciles & 11.roe & 12.roe & l1.roe & 2.roe \\
\hline $1,2,3$ & .416 & .356 & .459 & .359 \\
\hline $4,5,6$ & .290 & .230 & .304 & .196 \\
\hline $7,8,9$ & .148 & .069 & .138 & .098 \\
\hline
\end{tabular}

Source: Author.

As Table 5 shows, with an $\mathrm{R}^{2}$ of .925 for the ACV 1, 2, 3 cohort, it is clear that the model estimated on the 2001-2007 for the 1, 2, 3 cohort fits the data closely. By re-estimating after adding one year's data, one year at a time, we confirmed the stability of the model through the crisis and across time, again for the $1,2,3$ cohort. The $\mathrm{R}^{2}$ of these estimates ranged from a low of .923 in 2009 to a high of .931 in 2011.

Let us now return to Table 5 to explore the degree to which that stability shifts with the degree of control maintained by the different cohorts of banks. For the 1, 2,3 cohort, $R^{2}$ increased from the 2001 to 2007 estimates to those estimated on the 2001 to 2011 data. Again in Table 5, we can see that for cohort 4, 5, 6, $\mathrm{R}^{2}$ was between .728 and .755 while for the loosely managed cohort $7,8,9$ it was only .417 for the 2001-2007 estimates and considerably lower at .000 for the 2001-2011 regression.

The relatively high and consistent $\mathrm{R}^{2}$ results for the first six cohorts in the 2001-2007 and later estimates suggest that the core ACV model is an effective predictor of profitability if control is tight. And, if control is tight, the model aptly describes an essentially stable industry. We asked why.

The estimated $\beta$ coefficients of the two lags of ROE in the ACV partitioned regressions data point to a partial explanation. Refer to Table 6 and recall that the primary reason for including these two lags in the model was to control the serial correlation of in the error term. The $\beta$ estimates in Table 6 are substantially higher for the tightly controlled 1, 2, 3 cohort than for the cohorts that were loosely managed. Where control is looser, so, too, is the size of the estimated $\beta$ coefficients of the two lags of ROE.

These results in Tables 5 and 6, therefore, reflect both the serial correlation characterizing banking and the fact that when control is tight the "rule" holds that, on average, yesterday's performance predicts tomorrow's. These same results indicate that if control is loose, as for 7, 8, 9, that "rule" is considerably less reliable.

Mimicking Tables 5 and 6, the next table, Table 7, 'combines' the two and, so, summarizes the $\mathrm{R}^{2}$ and $\beta$ estimates for the first two lags of ROE for the LEVordered cohorts. These results are quite different from those in Table 5. The highest $\mathrm{R}^{2}$ in Table 5 is for the lightly leveraged cohort $1,2,3$ estimated on the 2001-2011 data. For the most leveraged banks (LEV cohort, 7, 8, 9), $\mathrm{R}^{2}$ ranges from 0.40 to 0.47 and, consistent with these results, the estimated $\beta$ coefficients of the two lags of ROE are quite low relative to those reported in Table 6 (our report of the ACV ordered analysis). The LEV partitioned regressions do not have the 
same ordered patterns of $\mathrm{R}^{2}$ for the model or the larger $\beta$ estimates for the lags of ROE that characterized the ACV partitioned results. Thus, because our focus in the next section of the paper is prediction, and because the LEV estimates were characterized by low $\mathrm{R}^{2}$ and small $\beta$ coefficients for the two lags of ROE, from this point forward we turn our attention back to the ACV partitions.

Table 7. Summary Results for the LEV Cohorts

\begin{tabular}{|l|c|c|c|c|c|c|c|c|c|}
\hline $\begin{array}{l}\text { Cohort } \\
\text { Deciles }\end{array}$ & \multicolumn{2}{|c|}{$\mathbf{R}^{2}$ Estimated 2001 to designated year } & \multicolumn{2}{|c|}{$\boldsymbol{\beta} 2001-2007$} & \multicolumn{2}{|c|}{$\boldsymbol{\beta} 2001-2011$} \\
\hline $1,2,3$ & $\mathbf{2 0 0 7}$ & $\mathbf{2 0 0 8}$ & $\mathbf{2 0 0 9}$ & $\mathbf{2 0 1 0}$ & $\mathbf{2 0 1 1}$ & 11.roe & 12.roe & 11.roe & 12.roe \\
\hline $4,5,6$ & .41 & .59 & .59 & .56 & .56 & .15 & .10 & .18 & .12 \\
\hline $7,8,9$ & .47 & .40 & .44 & .46 & .46 & .10 & .08 & .15 & .14 \\
\hline
\end{tabular}

Source: Author.

\section{Predictions}

Moving forward, we deliberately shift our focus to the ACV partitions and the predictive performance of Equation 1 when estimated on these cohorts. The predictions estimated on 2001-2007 are found in Table 8 in the third row, under the columns headed "if year $=20 X X$." They can be compared with the actual mean quarterly ROE experienced by the banks of each cohort as recorded in the top row of that section of Table 8 for the 1,2, 3 cohort. The results for the other two sets of cohort deciles are reported below the 1,2,3 results.

How closely does the model predict the actual ROE of each of the three decile cohorts in "future" years? In general, as Table 8 shows, the model parameterized on 2001-2007 data predicts future ROEs quite well for the 1,2, 3 cohort, even four years out from 2007 to 2011, confirming the stability of the industry and the performance of the model itself for the tightly controlled banks consistent with the results reported in Tables 5 and 6 . For example, the slightly pessimistic predictions of the 2001-2007 models for cohort 1, 2, 3 are for the most part only slightly lower than the actual ROE achieved. The ROE of these tightly managed banks was close to the "predicted" performance in every year. The predictions of the same model, for this same 1,2, 3 cohorts when estimated on a series of longer time lines, are also generally consistent with the 2001-2007 predictions even until 2011.

When we move down to the 4, 5, 6 cohort in Table 8, again the model predicts ROE reasonably well but, in contrast with the predictions for the 1, 2, 3 cohort, these are more pessimistic versus the actual results achieved by the 4, 5, 6 banks. These somewhat more loosely managed banks, although more buffeted by the 2008-2009 crisis than their 1,2, 3 rivals, beat predictions by a substantial margin after 2008. This is evidence of management's ability to re-establish control. It is also consistent with the evidence of Figure 2 which documented that very few banks suffered losses in more than two quarters of 2008 and 2009. Note from the left-hand side of Table 1 and two upper sections of Table 8 , that the ROE of banks in the 4, 5, 6 cohort was lower than that earned by the 1,2, 3 banks year after year.

As Table 8 makes clear, for the 7, 8, 9 cohort, the predictions are at first pessimistic then increasingly very, very optimistic. We have to conclude, 
therefore, that the evidence provided by these oscillating predictions is consistent with the implicitly reduced fit of our model to the data as indicated by the relatively low $\mathrm{R}^{2}$ in Table 5 and the smaller estimated $\beta$ coefficients of the two lags of the dependent variable for the 7, 8, 9 cohort in Table 6 .

When control on the tight-to-loose spectrum is near or just below the $7^{\text {th }}$ decile (in ACV rank), the high levels of predictability and profitability that characterized the more tightly controlled banks fails. Note that the actual annual ROE results for these loosely controlled cohorts are considerably lower than the results achieved by either of the more tightly managed sets of cohorts in this study. However, we can also note from the actual ROE achieved by the loosely managed 7, 8, 9 cohort in 2010 and 2011 that, on average, their management teams were able to slowly lift profitability from the depths reached in 2009.

Table 8. ACV Partitions Actual and Predicted Quarterly Mean ROE

\begin{tabular}{|l|c|c|c|c|c|c|}
\hline $\begin{array}{c}\text { Cohort } \\
\text { Deciles }\end{array}$ & Year & $\mathbf{2 0 0 7}$ & $\mathbf{2 0 0 8}$ & $\mathbf{2 0 0 9}$ & $\mathbf{2 0 1 0}$ & $\mathbf{2 0 1 1}$ \\
\hline $\mathbf{1 , 2 , 3}$ & $\begin{array}{c}\text { Actual Q } \\
\text { Mean ROE }\end{array}$ & .0353 & .0336 & .0290 & .0288 & .0285 \\
\hline & Base & Predictions & $\begin{array}{c}\text { If year = } \\
\mathbf{2 0 0 8}\end{array}$ & $\begin{array}{c}\text { If year } \\
\mathbf{2 0 0 9}\end{array}$ & $\begin{array}{c}\text { If } \text { year }= \\
\mathbf{2 0 1 0}\end{array}$ & $\begin{array}{c}\text { If } \text { year } \\
=\mathbf{2 0 1 1}\end{array}$ \\
\hline & $2001-2007$ & & .0330 & .0278 & .0260 & .0255 \\
\hline & $2001-2008$ & & & .0285 & .0270 & .0263 \\
\hline & $2001-2009$ & & & & .0265 & .0263 \\
\hline & $2001-2010$ & & & & & .0269 \\
\hline & $2001-2011$ & & & & & \\
\hline $\mathbf{4 , 5 , 6}$ & $\begin{array}{c}\text { Actual Q } \\
\text { Mean ROE }\end{array}$ & .0321 & .0262 & .0189 & .0232 & .0240 \\
\hline & $2001-2007$ & & .0251 & .0144 & .0164 & .0178 \\
\hline & $2001-2008$ & & & .0148 & .0187 & .0181 \\
\hline & $2001-2009$ & & & & .0185 & .0181 \\
\hline & $2001-2010$ & & & & & .0173 \\
\hline & $2001-2011$ & & & & & \\
\hline $\mathbf{7 , 8 , 9}$ & $\begin{array}{c}\text { Actual Q } \\
\text { Mean ROE }\end{array}$ & .0241 & .0162 & .0088 & .0115 & .0150 \\
\hline & $2001-2007$ & & & & & \\
\hline & $2001-2008$ & & & .0075 & .0056 & .0795 \\
\hline & $2001-2009$ & & & & .0073 & .0766 \\
\hline & $2001-2010$ & & & & & .0636 \\
\hline & $2001-2011$ & & & & & \\
\hline
\end{tabular}

Source: Author.

\section{Discussion}

\section{$A C V$ and LEV: Significance and Impacts}

The results indicate that both ACV and LEV are significantly correlated with ROE. However, by extending the analysis, we were able to establish that the 
standardized effect of ACV on ROE was considerably less than the effect of LEV during the 2001-2011 era for the ACV ordered cohorts. It is also clear that the effect of ACV on ROE rose quite dramatically through the crisis years of 2008 and 2009 for all cohorts. For example, in Table 9, we have our assessments of the standardized impacts of ACV and LEV for the 1, 2, 3 cohort from 2001-2007 and then for 2001-2011 (where $\left.b_{x}=\beta_{x} * \mathrm{Sd}_{\mathrm{x}} / \mathrm{sd}_{\mathrm{y}}\right)$.

Table A1.3 Impacts of a One Standard Deviation Change in ACV and Leverage on ROE 2001-2007 and 2001-2011(Calculated on ACV Partitioned Three Decile Cohorts)

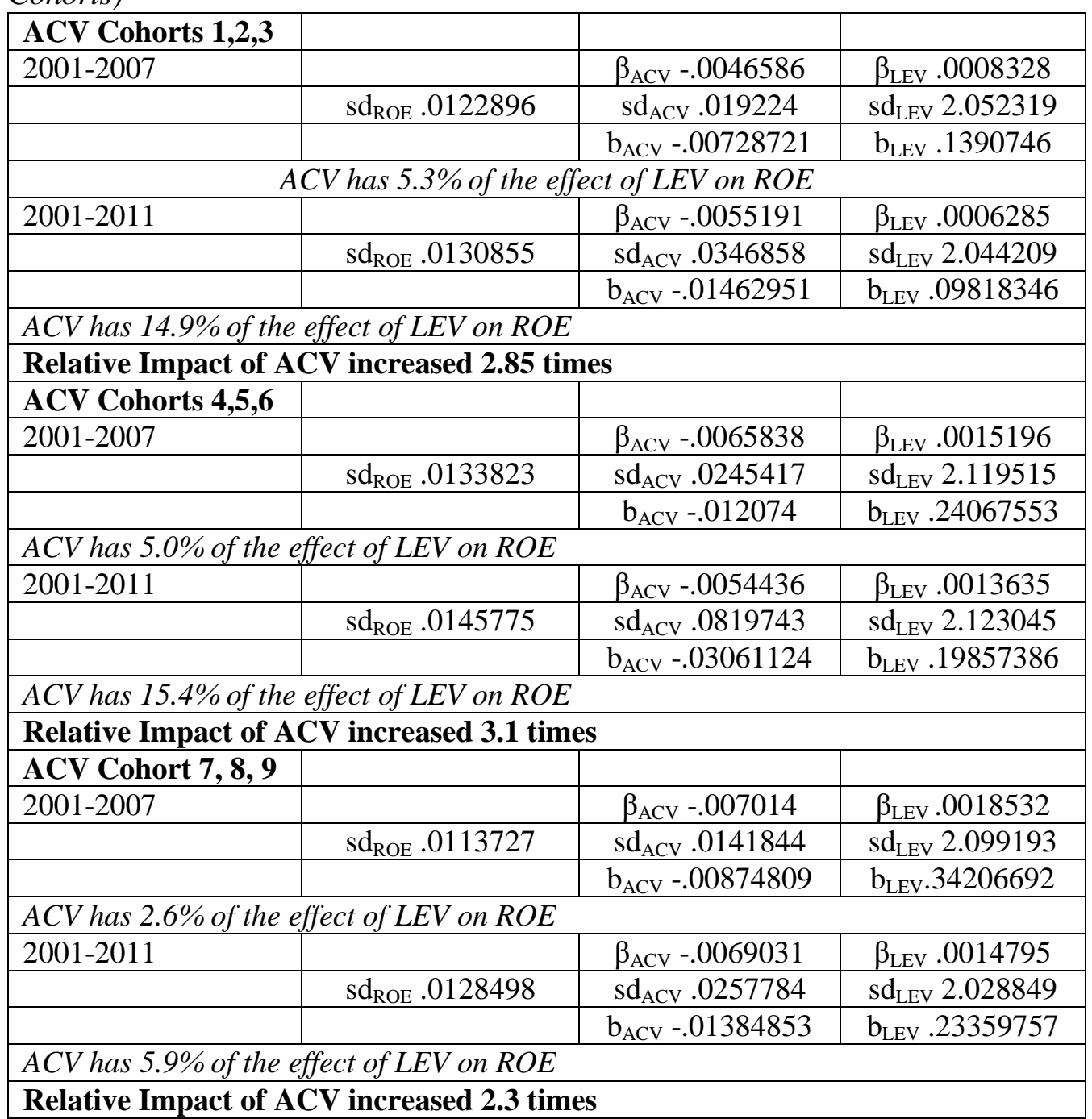

Source: Author.

Comparisons of the impacts of ACV and LEV in Table 9 for all cohorts shows that the impact of ACV on ROE in both the 2001-2007 and 2001-2011 ACV partitioned series was smaller than the LEV effect. But Table 9 also shows that by 2011, the impacts of ACV on ROE had increased substantially for every cohort set. Furthermore, as the impact of ACV increased, Table 9 also shows that the impact of LEV decreased. Control became ever more important to bank 
profitability after 2007. Appendix 1, Table A1.3 provides further detail with respect to Table 92001-2007 and then for 2001-2011 (where $b_{x}=\beta_{\mathrm{x}} * \mathrm{Sd}_{\mathrm{x}} / \mathrm{sd}_{\mathrm{y}}$ ).

The implication of these different trends seems clear: Control matters more when the financial markets are turbulent. This is true for all ACV cohorts. Tighter control is correlated with increased profitability in every year in our study but its effects increase when the banking industry is in crisis. Indeed, no matter the relative size of the statistical effects of the two variables, there are circumstances where banks may find a change in ACV can have an immediate impact exceeding the LEV effect. In Table 10, we move away from standardized impacts to "mean" impacts and turn from the 2007 and 2011 estimates to estimates ending with the crisis years, 2008 and 2009.

Table 9. Impacts on ROE of a One Standard Deviation Change in ACV or LEV

\begin{tabular}{|l|c|c|c|c|}
\hline $\begin{array}{l}\text { Cohort } \\
\text { Deciles }\end{array}$ & $\begin{array}{c}\text { Standardized } \\
\text { ACV Effect }\end{array}$ & $\begin{array}{c}\text { Standardized } \\
\text { Leverage } \\
\text { Effect }\end{array}$ & $\begin{array}{c}\text { Increase in } \\
\text { Standardized ACV } \\
\text { Effect 2007-2011 }\end{array}$ & $\begin{array}{c}\text { Increase in } \\
\text { Standardized } \\
\text { LEV Effect } \\
\mathbf{2 0 0 7 - 2 0 1 1}\end{array}$ \\
\hline $\mathbf{1 , 2 , 3}$ & & & & \\
\hline $\begin{array}{l}2001- \\
2007\end{array}$ & -.0073 & .139 & & 0.71 times \\
\hline $\begin{array}{l}2001- \\
2011\end{array}$ & -.0146 & .098 & 2.04 times & \\
\hline $\mathbf{4 , 5 , 6}$ & & & & \\
\hline $\begin{array}{l}2001- \\
2007\end{array}$ & -.012 & .241 & & 0.83 times \\
\hline $\begin{array}{l}2001- \\
2011\end{array}$ & -.031 & .199 & 2.53 times & \\
\hline $\mathbf{7 , 8 , 9}$ & & & & 0.68 times \\
\hline $\begin{array}{l}2001- \\
2007\end{array}$ & -.0087 & .342 & & \\
\hline $\begin{array}{l}2001- \\
2011\end{array}$ & -.0138 & .234 & 1.58 times & \\
\hline
\end{tabular}

Source: Author.

Consider the crisis year 2009 for the least controlled banks (cohort 7, 8, 9) in Table 10 - the bottom row. In Table 10, we calculate the effect of ACV and LEV on ROE when ACV and LEV are at their respective means. To do so, we multiply the estimated $\beta$ coefficients for each variable for the $7,8,9$ cohort by that variable's mean value to provide an estimated effect. Note the estimated $\beta_{\mathrm{ACV}}$ for 2001-2009 was -.0100 while the mean ACV for the 7, 8, 9 cohort in 2009 was .9227 yielding a -.0092 expected effect on ROE. The estimated $\beta_{\text {LEV }}$ was .0015 for 2001-2009 and, so, with the mean of LEV being 10.723 in 2009, LEV at its mean yielded a 0.017 ROE effect in the 2001-2009 estimates. These numbers are worth further consideration. As we will explain, during the crisis years, tightening control and reducing ACV may have offered a faster and more achievable profit impact than increased LEV. Table 10 is not the full story. 
Table 10. Mean Effects of ACV (Control) and LEV, 2008 and 2009 (ns - not Significant; $n c-$ not Calculable)

\begin{tabular}{|l|c|c|c|c|c|c|c|c|}
\hline $\begin{array}{l}\text { Cohort } \\
\text { Deciles }\end{array}$ & $\begin{array}{c}\text { End } \\
\text { Year }\end{array}$ & $\boldsymbol{\beta}_{\text {ACV }}$ & $\begin{array}{c}\text { Mean } \\
\text { ACV }\end{array}$ & $\begin{array}{c}\text { ACV } \\
\text { Effect }\end{array}$ & $\boldsymbol{\beta}_{\text {LEV }}$ & $\begin{array}{c}\text { Mean } \\
\text { Leverage }\end{array}$ & $\begin{array}{c}\text { LEV } \\
\text { Effect }\end{array}$ & $\begin{array}{c}\text { ACV/LEV } \\
\text { Effect }\end{array}$ \\
\hline $\mathbf{1 , 2 , 3}$ & 2008 & -.0064 & .0783 & -.0006 & .0008 & 10.857 & .008 & $7.5 \%$ \\
\hline & 2009 & -.0084 & .1246 & -.0011 & .0006 & 10.653 & .006 & $18.3 \%$ \\
\hline $\mathbf{4 , 5 , 6}$ & 2008 & -.0084 & .1926 & -.0016 & .0015 & 10.879 & .016 & $10.0 \%$ \\
\hline & 2009 & $\mathrm{~ns}$ & .3356 & $\mathrm{nc}$ & .0014 & 10.503 & .015 & $\mathrm{nc}$ \\
\hline $\mathbf{7 , 8 , 9}$ & 2008 & -.0147 & .5106 & -.0075 & .0016 & 10.702 & .017 & $44.1 \%$ \\
\hline & 2009 & -.0100 & .9227 & -.0092 & .0015 & 10.723 & .017 & $54.7 \%$ \\
\hline
\end{tabular}

Source: Author.

The point is that in 2009, the year that many banks suffered their largest losses, and when on average ACV was at its highest levels, for the most loosely controlled $(7,8,9)$ banks, we'll argue that tightening ACV promised a faster and more sure return than increased leverage. For any bank, changing leverage is not a short-term matter because changing leverage is only possible if there are appropriate investment and liquidation opportunities available in the market (Rosengren 2008). Finding sound new investment opportunities is likely to be impossible for most banks in a financial crisis as is the task of quickly eliminating problem loans. Calabia (2016) pointed out that even in 2015, some banks were still working their way out of loan problems that had developed during the crisis.

Further in this regard, as the data in Figure 2 show, most of the banks that suffered quarterly losses in 2008 or 2009 were able to re-establish control and limit those losses to one or two quarters. The greater majority of America's banks proved to be quite resilient. Recall, too, that $70 \%$ avoided an annual loss notwithstanding the crisis. The accumulated evidence is, therefore, that tightening control is demonstrably more feasible in the short term than increasing leverage.

\section{Predictability}

Overall, our model of the US banking industry's profitability performed well as measured by the $\mathrm{R}^{2}$ we reported and by the small differences between predicted and actual performance for the 2001-2007 model and those estimated on longer time lines. The results for the first two large cohorts - the first six ACV deciles suggest that tight control pays with higher and more predictable performance (ROE). The estimates for deciles 7, 8 and 9 had lower $\mathrm{R}^{2}$ and poor predictive performance.

Table 8 showed that when control was tight, that is, when ACV was small, as it was for the 1, 2, 3 cohort, the 2001-2007 model predicted ROE one year at a time effectively, even four years out. The models for cohort $1,2,3$ enjoyed $\mathrm{R}^{2}$ of .90 or greater. For this cohort, the statement that today's results offer reasonable predictions of tomorrow's holds on average. Cohort 4, 5, 6 had $\mathrm{R}^{2}$ of .70 and greater. Models estimated on 2001 to 2010 also predicted well for cohorts 4, 5, 6 .

When the data used to estimate our models described the more loosely controlled banks of cohort 7,8,9, our ability to predict faded dramatically as noted. Here predictions oscillated from quite pessimistic to very optimistic 
reflecting the instability associated with lose control. Consistent with the $\mathrm{R}^{2}$ results reported earlier, the predictions measured how well the regression model was able to account for the variation of ROE.

When $\mathrm{R}^{2}$ and the predictive performance of the model fell off, as they did for the loosely controlled cohorts $7,8,9$, those failures imply that other influences, not captured by the model, had become more important. These might be considered special factors in the financial crisis. The regular pattern of lower $\mathrm{R}^{2}$ for banks with looser control indicates that banks that did not maintain tight control have been exposed to (or have effectively exposed them to) influences that adversely affect ROE, influences these banks are less able to manage than their more controlled rivals.

Dichev and Tang (2009) established that volatility was inversely related to earnings in a multi-industry study hypothesizing that economic shocks and accounting noise create volatility. They also found that the predictive power of their model dropped as the time horizon lengthened. Our results for banks are different and, although they show ROE changed through and after the 2008-2009 economic shock, explaining them does not require a deep understanding of the accounting difficulties some banks may have had providing appropriately for losses prior to determining earnings.

Our explanation for the banking industry is that control matters. The effect of control on ROE was persistent. When control was tight, profitability was high, $\mathrm{R}^{2}$ was high, and our predictions were quite close to the actual average ROE's earned by cohorts $1,2,3$. Predictions were reasonably close to the actual results for cohorts 4, 5, 6. Our models predicted performance whether estimated 2001-2007 or 2001-2011 through the 20082009 crisis. When control was loose, as it was for cohort 7,8, 9, however, profitability was lower, $\mathrm{R}^{2}$ was lower and the model did not predict effectively.

Persistence profit effects have been found by others. Fahlenbrach et al. (2012) showed that good performance in 1998 predicted good performance in 2008 and poor performance in 1998 predicted poor performance in 2008. These effects appear to have persisted for ten years. Because of that persistence, Fahlenbrach et al. (2012) explained their findings as being related to a persistent culture, not learning. For them, by 2008, learning would have stimulated performance improvements for many of the poor performers of 1998 but they found no such evidence. Fahlenbrach et al. (2012) explained their findings as evidence that over time, most banks sustained a culture that limited risk while others persistently accepted more risk. Also referring to the importance of culture, Baxter (2015) spoke to the importance of ethical decision making in the bank's management cadres. Hatten et al. (2004) found the performance effects of Miles and Snow's (1978) decision making archetypes in the banking industry, that we see as cultural attributes, were sustained for at least ten years. The evidence in total suggests that bank performance, whether good or poor, is likely to be sustained. Measuring culture seems complex. Measuring control is a little simpler although we can see that persistent control might be seen as a cultural attribute of any organization.

Because we gave greater attention to serial correlation in the error term than both Dichev and Tang (2009) and Fahlenbrach et al. (2012), we think that our 
results support our conclusion that managerial control has an important influence on bank performance. Our control proxy, ACV, clearly discriminated high from low performers before, through and beyond the crisis. The model (Equation 1) predicted performance quite well, when control was tight. Our results, therefore, offer a tentative explanation for bank ROE and its variation, and for the persistence of that performance: Variation is limited by tight control and magnified if lose control prevails.

To sum up, the signs of each of these primary variables, negative for ACV and positive for LEV, matched expectations. No matter the cohorts involved, the near universal significance of both ACV (negative) and LEV (positive), and the $\mathrm{R}^{2}$ achieved in our regressions promotes confidence that control matters. Consistent patterns of significance among the statistical control variables and the fixed time effects included in the model gave us further confidence in its reliability and conclusions drawn on the results. With respect to the statistical control variables, it is interesting to note that bank size (the log of total bank assets - lnta) was not significant except for the 4, 5, 6 cohort where it had a negative sign in the 20012007 and 2008 estimates. Real estate interest as a fraction of total interest (reinterest/all interest) was not significant throughout this study. This non-finding is worth noting since the financial crisis (and contraction of credit) is generally believed to be closely related to real estate problems. Our results suggest that in the banking industry, per se, poor real estate investments characterized only small numbers of banks as studies of bank failures have shown (Aubuchon and Wheelock 2010, Gopalan 2010, Robinson 2010, GAO 2013).

We included six to ten fixed time effects with 2007 being the omitted referent year. Throughout the study, the time effects for 2001 were not significant. It appears that economic conditions at the end of the prior business cycle in 2001 were similar to those at the end of 2007 immediately before the crisis. The time effects thereafter, 2002 to 2011, were significant and positive for cohorts 1 through 6. For cohort 7, 8, 9, the same results prevailed except for 2008 and 2009 where the fixed effects coefficients for these two years were not significant. In general, and ceteris paribus, the positive time effects relative to the ROE of 2007 were smallest in the 1, 2, 3 regressions and largest for 7, 8, 9. They were larger in 2004 than in earlier years for all cohorts. Then they decreased. They increased again for the 4, 5, 6 and 7, 8, 9 cohorts in 2010 and 2011. These results indicate that the model captured the recovery. The largest coefficient for any time effect in 2010 and 2011 was .0074 for 4, 5, 6 in 2010 when that cohort's average quarterly ROE was only 0.0231 .

\section{Limitations and Future Research}

In this study, we focused on control and leverage, and the degree to which the performance of US banks through the 2008-2009 crises was predictable. This study does not address how bankers maintain or re-establish control when needed. It is important to note that our results pertain to the "on average" performance of specific cohorts of banks - by observation, even banks in the most controlled 
cohorts can experience losses and, when they do, if profits fall far enough to cut equity, ACV will fall with them. The data suggest that losses can occur in any loan portfolio when a bank's clients get into trouble. In such circumstances, we suggest that anticipation is a better strategy for loan management than reaction because working out from troubled loans can take years (Calabia 2016).

In this study we did not directly address the role of Fed Policy or particular aspects of the greater US economy and their influence on ROE. However, as noted above, the model (Equation 1) included 18 to 22 statistical controls. Twelve of these represent attributes of the banks and their markets. The others, six to ten in total, were fixed time effects for the years included in the estimates, initially 20012007, and finally 2001-2011. However, we could not interpret these significant and positive year by year time effects as representing particular Fed Policies or economic conditions. (There were too many quarters [up to 40] to allow a similar study at that level). Future research using different types of models might be used to ascertain whether and how the banking industry reacted to such exogenous forces as Fed Policy and whether the effects of control and leverage on ROE shift in any way when the exogenous environment is more explicitly addressed. Finally, there is the matter of growth. Although we included bank size (ln total assets) in the statistical controls, we did not explicitly address either growth (Fahlenbrach et al. 2012) or the role of shadow banking (Stein 2012, Papanikolaou and Wolff 2014) in determining the performance of the crisis survivors in our sample. The literature suggests that each of these factors is of greater relevance in explaining failures. Our focus was survivors. In this study, the very high $\mathrm{R}^{2}$ and the predictive performance of the models explaining ROE in light of control and leverage when control is tight suggests that the models used are quite effective and that control is important.

\section{Conclusion}

The first research question was: how did the surviving banks do it? To address this question, we set out to determine whether and how control and leverage impacted ROE. Our results show that both leverage (measured as LEV) and control (measured as ACV) have significant influences on ROE. Overall, our model was designed to manage serial correlation of the error term, performed well in the 2001-2011 period, and provided accurate descriptions of the industry through the crisis, once again we add, especially when control was tighter than the $7^{\text {th }}$ decile on the ACV-ordered data. As expected, the effect of leverage on ROE was positive and the effect of control (ACV) was negative. Leverage had a larger standardized direct impact on profitability than control, no matter the degree of control achieved.

The answer to the first research question is that the survivors did it with control. Tight control afforded higher and more stable profitability and, so, predictable performance measured both as $\mathrm{R}^{2}$ and with predictions close to actual ROE achieved. However, when control was loosened to beyond the $7^{\text {th }}$ decile (on the ACV ordered scale), predictability quickly waned and largely disappeared. 
The second question was: which had the larger effect? The answer is that leverage had the larger direct impact on ROE. Yet it is clear that data and results show that the highest ROEs are the province of the most tightly controlled banks. Control is a discriminating factor. Moreover, the most controlled banks weathered the 2008-2009 crises more successfully than the rest. Our regressions on the ACV ordered data establish that control matters, especially when times are bad.

For the tightly controlled banks, predictability helps establish the case that control is a determining factor in the banking industry no matter the relatively greater standardized effect of leverage. Even for the banks where predictability was low, its universally positive sign indicates that leverage did not drive them down. US banks were conservative users of leverage up to and through the crisis. As Appendix 1, Table A1.2 shows, 'on book' leverage in the US banking industry changed slowly from 2001-2011.

If not for the use of excessive leverage, what contributed to the severity of the financial crisis for some banks while others, although buffeted for a time, were able to recover more readily? In light of the evidence presented herein, we suggest that it was loose control that forced some bankers to react and to struggle. It was tight control that was correlated with higher returns and resiliency. However as noted above, for those in dire straits, the speed with which control can be reestablished is crucial. Control demands vigilance, anticipation and proactive action.

Here we note again that this is a descriptive study, not a prescriptive study. Control measured as ACV can be studied across the industry and time suggesting that ACV offers one additional opportunity for an analyst or regulator to monitor change in the banking industry. For some, this could mean identifying the most and the least resilient banks as times change.

This study does not present strategies to tighten control or manage a commercial loan portfolio. It supports the view that for the most part, American bankers know how to re-establish control and most know how to do it quickly - it seems to us that savvy bankers operate with a sound rule that avoiding losses should be given prominence over slightly higher profits. Prudent bankers "value" losses highly.

To conclude, what is the value of paying attention to control and monitoring ACV across the industry? ACV is another factor that bankers, analysts and regulators might monitor to help them assess the state of the banking industry and the economy throughout the business cycle. ACV is a measure which might help all of them widen the focus of their analysis from individual banks and peer groups to the industry. In this way, an industry-wide focus on ACV could supplement the customary focus on bank failures and size. Increased and sustained control is a counter to "too big to fail". ACV and control can be used to supplement and expand what is presently common practice. 


\section{References}

Anthony RN (1965) Planning and Control Systems: A Framework for Analysis. Division of Research, Graduate School of Business Administration, Harvard University: Boston, MA.

Aubuchon CP, Wheelock DC (2010) The geographic distribution and characteristics of U.S. bank failures, 2007-2010: do bank failures still reflect local economic conditions? Review, Federal Reserve Bank of St. Louis: 395-415. Retrived from https://bit.ly/2v bBFNp

Bartlett WF and King T (2008) Profits and balance sheet developments at U.S. commercial banks in 2007. Governors of the Federal Reserve System (U.S.) A1A39. Retrieved from https://bit.ly/2vhBMXV.

Baxter TC (2015 January) The Rewards of an Ethical Culture, Executive Vice President and General Counsel New York Fed. Remarks at the Bank of England London, 20.

Bowman EH (1980) A risk-return paradox for strategic management. Sloan Management Review Spring: 17-31.

Bromiley P, Miller KD, Rau D (2001) Risk in strategic management research. In Hitt MA, Freeman RE, Harrison JS (Eds). The Blackwell Handbook of Strategic Management, 259-288. Oxford, UK: Blackwell.

Calabia FC (2016) Community banking in an ever changing world. Remarks at the Community Bankers' Conference, Federal Reserve Bank of New York, New York City. April 7. Retrieved from https://bit.ly/2LQYPzz.

Calomiris CW, Meltzer AH (2014) How Dodd-Frank doubles down on 'too big to fail': two major flaws mean that the act doesn't address problems that led to the financial crisis of 2008. WSJ Opinion, Feb. 12, 6:44 p.m. ET.

Dichev ID, Tang VW (2009) Earnings volatility and earnings predictability. Journal of Accounting and Economics 47: 160-181.

Fahlenbrach R, Prilmeier R, Stulz RM (2012) This time is the same: using bank performance in 1998 to explain bank performance during the recent financial crisis. The Journal of Finance 67(6): 2139-2185.

Fayol H (1916) General and Industrial Management, First French Edition, trans. Constance Storrs. New York: Pitman Publishing, 1972.

Gopalan YK (2010 Spring) Earliest indicator of bank failure is deterioration in earnings. Central Banker Federal Reserve Bank of St. Louis. Retrieved from https://bit.ly/2A pnaLV.

Government Accountability Office (2013 January) Report to Congressional Committees: Financial institutions: causes and consequences of recent bank failures. United States Government Accountability Office (GAO-13-71). Retrieved from https://bit.ly/ 2ybRpAp.

Hatten KJ, James WL, Meyer DG (2004) The longevity of the performance effects of the Miles and Snow strategic archetypes: a ten-year perspective in US banking. International Journal of Management and Decision Making 5(2/3): 196-215.

Juran JM (1989) Juran on Leadership for Quality: An Executive Handbook. New York: Free Press.

Marsh TA, Swanson DS (1984) Risk-return tradeoffs for strategic management. Sloan Management Review Spring: 35-51.

Miles RE, Snow CC (1978) Organizational Strategy, Structure and Process. Palo Alto, CA: Stanford University Press.

Nickel MN, Rodriguez MC (2002) A review of research on the negative accounting relationship between risk and return: Bowman's paradox. Omega 30: 1-18. 
Papanikolaou NI, Wolff CCP (2014) The role of on- and off-balance-sheet leverage of banks in the late 200's crisis. Journal of Financial Stability 14: 3-22.

Robinson KJ (2010) Eleventh district banking industry weathers financial storms. Federal Reserve Bank of Dallas. Southwest Economy Q2: 3-7. Retrieved from https://bit.ly/ 2LSZr85.

Rosengren ES (2008) Implications of a credit crunch. President Federal Reserve Bank of Boston, Speech at the Business and Industry Association of New Hampshire and the Greater Manchester Chamber of Commerce, Manchester, New Hampshire, September 3.Retrieved from https://bit.ly/2AfXEsf.

Rothschild M, Stiglitz JE (1970 September) Increasing risk I: a definition. Journal of Economic Theory 2(3): 225-243.

Rothschild M, Stiglitz JE (1971 March) Increasing risk II: its economic consequences. Journal of Economic Theory 3(1): 66-84.

Ruefli TW (1990 March) Mean-variances approaches to risk return relationships in strategy: paradox lost. Management Science 39(3): 368-380.

Shewhart WA (1984) Statistical Method from the Viewpoint of Quality Control. Dover: New York (a re-publication of the 1939 edition published by Graduate School, Department of Agriculture: Washington, D.C).

Stein JC (2012) Monetary policy as financial stability regulation. The Quarterly Journal of Economics 127: 57-95.

Walton M (1986) The Deming Method. Berkley Publishing: New York. 


\section{Appendix 1}

Leverage Record 2001-2011*

\begin{tabular}{|l|l|l|l|l|l|l|l|l|l|}
\hline Year & \multicolumn{3}{|c|}{ Cohorts 1, 2, 3 } & \multicolumn{3}{c|}{ Cohorts 4, 5, 6 } & \multicolumn{3}{c|}{ Cohorts 7, 8, 9 } \\
\hline & mean & min & max & mean & min & max & mean & min & max \\
\hline 2001 & 8.61 & 6.11 & 10.19 & 11.11 & 10.20 & 11.96 & 12.85 & 11.97 & 14.01 \\
\hline 2002 & 8.63 & 6.14 & 10.11 & 11.00 & 10.11 & 11.81 & 12.66 & 11.81 & 13.81 \\
\hline 2003 & 8.60 & 6.12 & 10.00 & 10.91 & 10.01 & 11.74 & 12.58 & 11.74 & 13.69 \\
\hline 2004 & 8.61 & 6.14 & 9.99 & 10.82 & 9.99 & 11.65 & 12.54 & 11.65 & 13.67 \\
\hline 2005 & 8.51 & 6.17 & 9.96 & 10.82 & 9.96 & 11.63 & 12.61 & 11.63 & 13.91 \\
\hline 2006 & 8.41 & 6.17 & 9.79 & 10.72 & 9.79 & 11.55 & 12.56 & 11.55 & 13.95 \\
\hline 2007 & 8.30 & 6.16 & 9.60 & 10.48 & 9.60 & 11.28 & 12.22 & 11.28 & 13.55 \\
\hline 2008 & 8.30 & 6.21 & 9.60 & 10.48 & 9.60 & 11.34 & 12.24 & 11.34 & 13.55 \\
\hline 2009 & 8.26 & 6.22 & 9.52 & 10.34 & 9.52 & 11.11 & 12.05 & 11.12 & 13.34 \\
\hline 2010 & 8.00 & 6.19 & 9.18 & 9.98 & 9.18 & 10.70 & 11.55 & 10.70 & 12.75 \\
\hline 2011 & 7.76 & 6.16 & 8.83 & 9.61 & 8.83 & 10.34 & 11.18 & 10.34 & 12.39 \\
\hline
\end{tabular}

${ }^{*}$ The data were separately sorted by leverage in each year from light to high leverage and then partitioned into ten cohorts of equal size.

Quarterly Mean ROE RECORD of Leverage PARTITIONED COHORTS Low Rank Deciles are Banks with Low Leverage; High Rank Deciles Have High Leverage

\begin{tabular}{|l|c|c|c|c|c|c|c|c|c|c|c|}
\hline $\begin{array}{l}\text { Cohort } \\
\text { Deciles }\end{array}$ & $\mathbf{2 0 0 1}$ & $\mathbf{2 0 0 2}$ & $\mathbf{2 0 0 3}$ & $\mathbf{2 0 0 4}$ & $\mathbf{2 0 0 5}$ & $\mathbf{2 0 0 6}$ & $\mathbf{2 0 0 7}$ & $\mathbf{2 0 0 8}$ & $\mathbf{2 0 0 9}$ & $\mathbf{2 0 1 0}$ & $\mathbf{2 0 1 1}$ \\
\hline & & & & & & & & & & & \\
\hline $\mathbf{1 , 2 , 3}$ & .0260 & .0289 & .0280 & .0272 & .0270 & .0261 & .0230 & .0171 & .0132 & .0161 & .018 \\
\hline $\mathbf{4 , 5 , 6}$ & .0317 & .0331 & .0316 & .0317 & .0334 & .0327 & .0294 & .0233 & .0173 & .0192 & .021 \\
\hline $\mathbf{7 , 8 , 9}$ & .0363 & .0369 & .0358 & .0356 & .0361 & .0348 & .0319 & .0260 & .0209 & .0231 & .023 \\
\hline
\end{tabular}


